\title{
PERFORMANCE CONFIRMATION FOR AN MGDS AT YUCCA MOUNTAIN
}

\author{
By Brent Thomson and Carl Vecchione \\ TRW Environmental Safety Systems, Inc. \\ 1180 Town Center Drive, Las Vegas, Nevada 89134
}

\section{Introduction}

Performance confirmation is the program of tests, experiments, and analyses, which is conducted to evaluate the accuracy and adequacy of the information used to determine with reasonable assurance that the performance objectives for the period after permanent closure will be met. This program begins during site characterization and continues until permanent closure. The program will collect and analyze data needed to reduce uncertainties in postclosure performance and verify the performance of the structures, systems, and components important to waste isolation. The Performance Confirmation Program is a part of the Mined Geologic Disposal System (MGDS) Test and Evaluation (T\&E) Program, which performs verification for the entire MGDS.

\section{Relationship to the MGDS Test and Evaluation Program}

The MGDS Test and Evaluation Program functions include: determining suitability of the Yucca Mountain Site for housing a geologic repository; conducting proof of design concept testing to reduce development risk; verifying structures, systems, and components, compliance with design requirements and specifications; performing system testing to validate MGDS requirements including the receipt, handling, retrieval, and disposal of waste; conducting periodic performance testing to 
verify preclosure requirements and demonstrate safe and reliable MGDS operation; and performing modeling, test, and analysis to verify postclosure regulatory requirements. To perform these functions, the MGDS T\&E Program is divided into five major functional areas: Site Characterization Test and Evaluation, Developmental Test and Evaluation, Operational Test and Evaluation, Periodic Performance Testing, and Performance Confirmation. An overview of the MGDS T\&E Program is shown in Figure 1. The Mined Geologic Disposal System Viability Assessment Test and Evaluation Plan $^{1}$ is a description of the Test and Evaluation Program for the MGDS. Although performance confirmation is discussed in this plan, it is not the focus of the plan. Performance confirmation activities are described in the Performance Confirmation Plan ${ }^{2}$.

\section{Performance Confirmation Plan}

The Performance Confirmation Plan defines the activities necessary to conduct the Performance Confirmation Program as specified in 10 CFR Part 60, Subpart F. This plan is used as the basis for detailed planning of the Performance Confirmation Program and facilities integration with the MGDS T\&E Program. This plan establishes requirements for testing and contains requirements on facilities and equipment necessary to perform the testing functions. An initial set of these requirements was captured in the Controlled Design Assumptions Document ${ }^{3}$. The Performance Confirmation Plan recommended some changes to these requirements. The design has used these requirements from the Controlled Design Assumptions Document to develop designs of performance confirmation facilities and systems. 


\section{Objectives and Approach}

The Performance Confirmation Program objectives are 1) to confirm that subsurface conditions encountered and changes in those conditions during construction and waste emplacement operations are within the limits assumed in the License Application; 2) confirm that natural and engineered systems and components that are required for repository operations, or that are designed or assumed to operate as barriers after permanent closure, are functioning as intended and anticipated; 3) evaluate compliance with U.S. Nuclear Regulatory Commission (NRC) postclosure performance requirements; and 4) evaluate the repository readiness for permanent closure.

To meet the above objectives the Performance Confirmation Program will apply a six-step approach (See Figure 2). The first step is to define a performance confirmation baseline. This baseline identifies the processes and parameters important to postclosure performance. The second step is to predict values and variations of critical performance measures for the parameters in the performance confirmation baseline, which establishes expectations during construction and operations. The third step is to establish tolerances or limits on deviations from predicted performance. The fourth step is to monitor performance, perform tests and collect data. The fifth step is to analyze and evaluate the data, including process model validation, analyses, statistical tests, and total system performance assessments. The sixth step is to recommend and implement appropriate actions, if there are deviations from what was predicted or assumed. If there are no deviations, or when the closure criteria are satisfied, the Program will evaluate the repository readiness for permanent closure. 

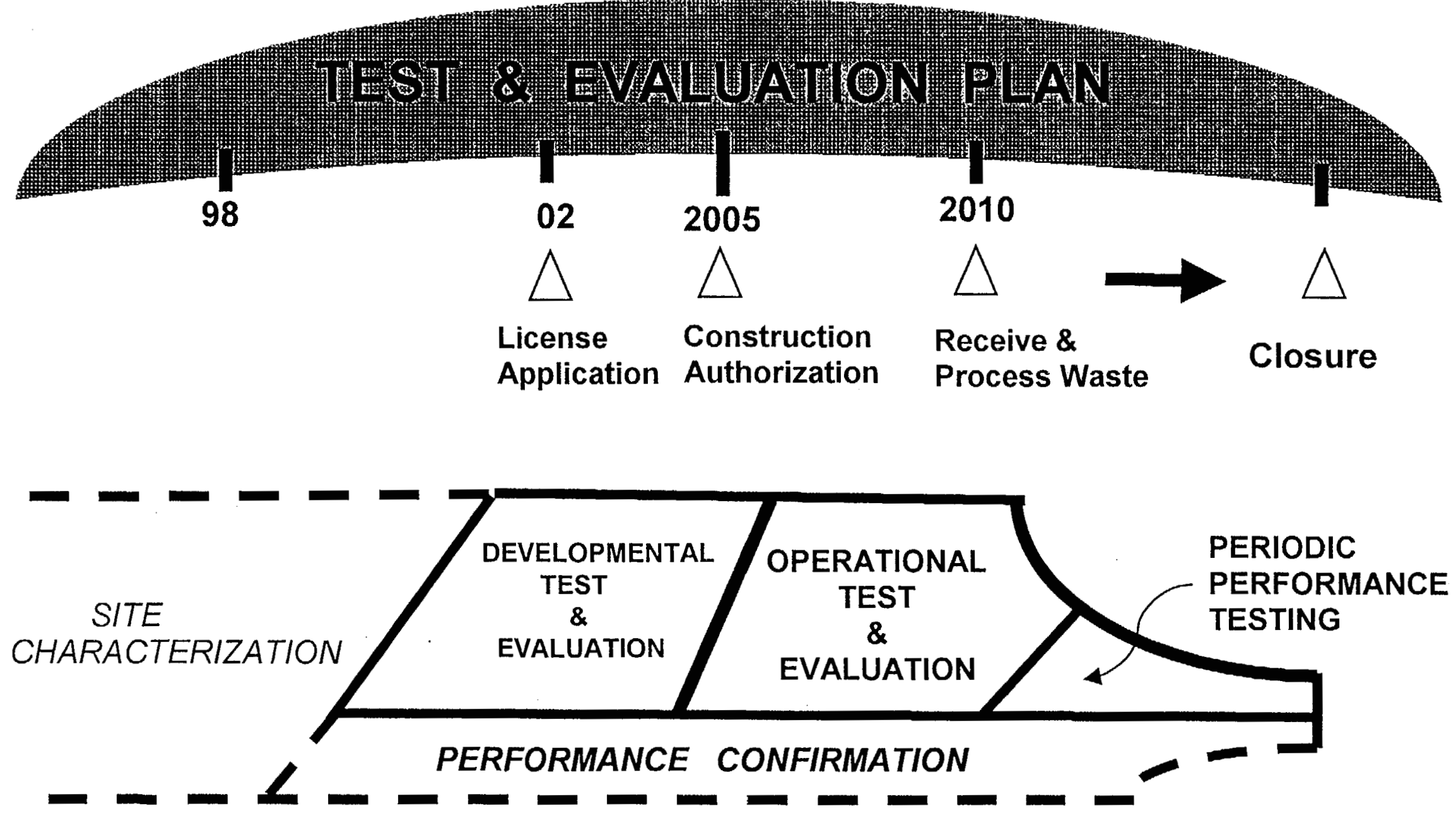


\section{Performance Confirmation Concepts}

Performance confirmation concepts for measuring, monitoring, observing, and testing the performance confirmation parameters selected and evaluating the natural and engineered barrier processes are summarized in Table 1. These concepts describe the types of activities necessary for performance confirmation data acquisition and for performance confirmation facilities and support. Each concept is defined, as applicable, in terms of (a) the parameters to be confirmed and (b) the facilities and equipment to be used. Generally, the concepts do not identify specific locations and frequencies for the activities, instrumentation, and monitoring and testing procedures; these will be defined in separate design specifications and activity plans. One activity in particular involves subsurface geologic mapping and sampling during construction. The amount of mapping required influences the ground control system design and the cost of the MGDS.

\section{Conclusions}

The Performance Confirmation Plan identifies the objectives, approach, and planned activities to implement the Performance Confirmation Program. As an example of the type activities planned, a strategy for mapping during repository construction was recommended in the Performance Confirmation Plan. The recommendation is to: 1) map approximately 10 percent of the emplacement drifts, based on the current drift spacing and layout; 2) map non-emplacement drift openings; and 3) observe rock mass conditions for anomalous conditions during construction. The rationale for mapping approximately 10 percent of the emplacement drifts is that the frequency of mapped drifts is selected to assure intersection of features anticipated to affect repository performance. Present 
surface mapping shows several faults with 200 - 300 meter fault trace lengths with the repository block. Most of these faults are expected to penetrate the host repository horizon and extend downward to the water table. The importance of these faults to repository performance is currently uncertain. A frequency of mapping approximately 10 percent of the emplacement drifts, at the current spacing, would provide reasonable confidence of intersecting these surface mapped features at depth. 


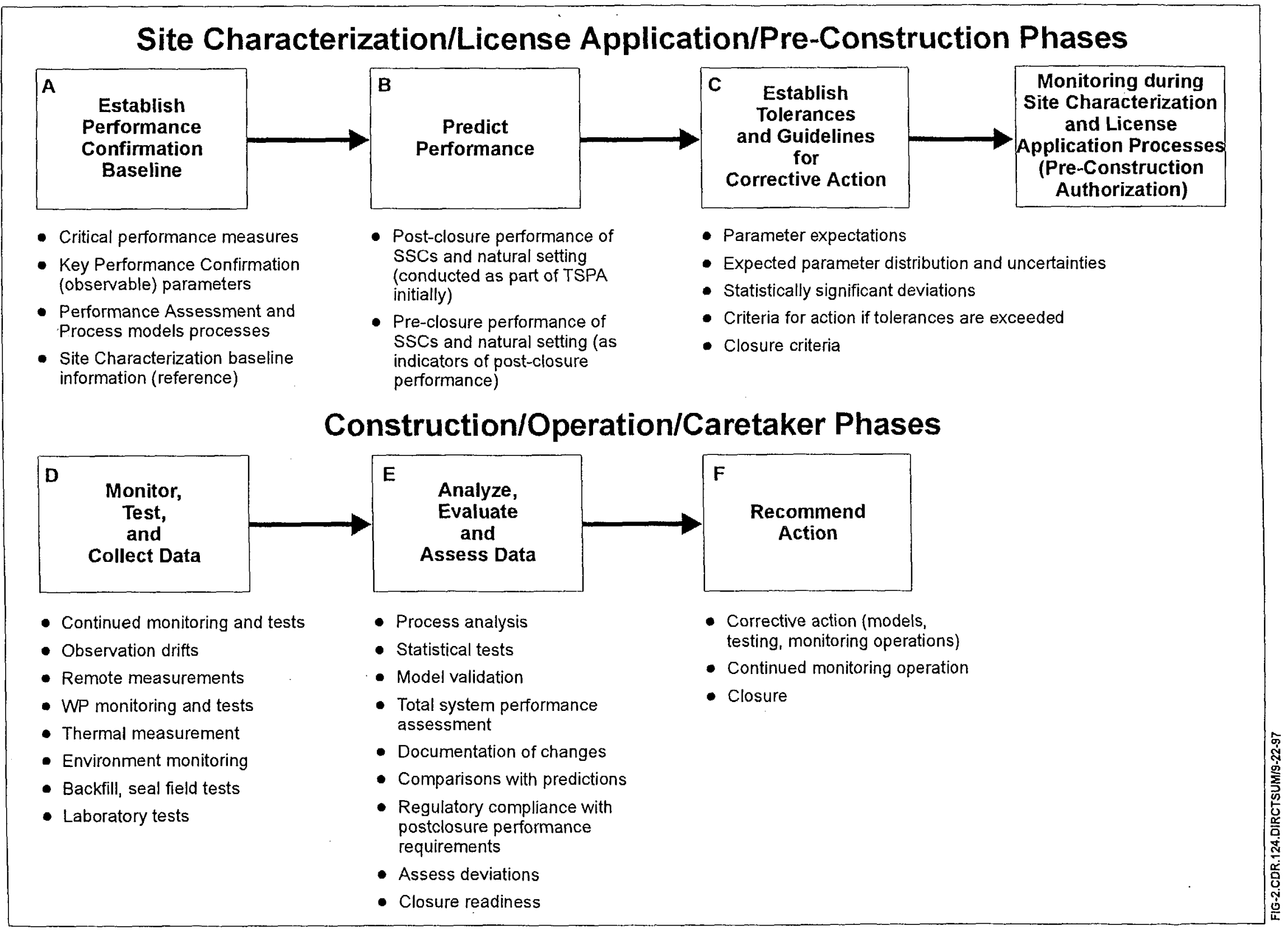

Figure 2. MGDS Performance Confirmation Approach 


\section{References}

1. Mined Geologic Disposal Systèm Viability Assessment Test and Evaluation Plan, B00000000-

01717-5705-00058 REV 00. TRW Environmental Safety Systems Inc., Las Vegas, Nevada.

2. Performance Confirmation Plan, B00000000-00841-4600-00002 REV 00. TRW Environmental

Safety Systems Inc., Las Vegas, Nevada.

3. Controlled Design Assumptions Document, B00000000-01717-4600-00032 REV 04, ICN 2.

TRW Environmental Safety Systems Inc., Las Vegas, Nevada.

Table 1. Performance Confirmation Concepts

\begin{tabular}{|l|l|l|}
\hline \multicolumn{1}{|c|}{ Group } & \multicolumn{1}{|c|}{ Subgroup } & \multicolumn{1}{|c|}{ Package/Concept } \\
\hline $\begin{array}{l}\text { 1. Monitoring and } \\
\text { testing concepts }\end{array}$ & $\begin{array}{l}\text { Site monitoring and } \\
\text { testing concepts }\end{array}$ & $\begin{array}{l}\text { Subsurface geologic mapping package } \\
\text { Surface-based unsaturated zone hydrology package } \\
\text { Underground fault zone hydrology package } \\
\text { Thermal testing package }\end{array}$ \\
\cline { 2 - 3 } & $\begin{array}{l}\text { Repository monitoring } \\
\text { and testing concepts }\end{array}$ & $\begin{array}{l}\text { In situ seals testing } \\
\text { In situ backfill testing } \\
\text { Follow-on drift heater testing } \\
\text { Subsurface seismic monitoring } \\
\text { Remote observation and inspection of emplacement drifts }\end{array}$ \\
\cline { 2 - 3 } & $\begin{array}{l}\text { Waste package } \\
\text { monitoring and testing } \\
\text { concepts }\end{array}$ & $\begin{array}{l}\text { Off-site laboratory testing } \\
\text { In situ monitoring } \\
\text { Recovered waste package testing, as a contingency } \\
\text { Recovered dummy waste package testing } \\
\text { Recovered non-radioactive specimen testing }\end{array}$ \\
\hline 2. Test facilities \\
and support \\
concepts
\end{tabular}

